Review Article

Kaleemullah Kalwar* and Ming Shen

\title{
Electrospun cellulose acetate nanofibers and Au@AgNPs for antimicrobial activity - A mini review
}

https://doi.org/10.1515/ntrev-2019-0023

Received Jan 26, 2019; accepted Sep 23, 2019

Abstract: Au@Ag nanoparticles decorated on cellulose paper could be worthful biomedical applications. Electrospinning technique is broadly employed for fabrication of nano and micro size fibers with a variety of biopolymers adding cellulose acetate nanofibers. Evolutions in cellulose research demonstrate that it is an anticipating material for the biomedical application. Nanofibers acquired by electrospinning technique were utilized in various biomedical applications. In this report, electrospinning of cellulose acetate, the solvent choice for cellulose acetate e-spun nanofabrication and decoration of AgNPs including shape and size for antimicrobial activity are argued.

Keywords: electrospinning technique; cellulose acetate; solvent; silver nanoparticles; antimicrobial activity

\section{Introduction}

Before the starting into electrospun cellulose acetate nanofibers, it would be productive to elaborate on the fundamentals of electrospinning technique. As the origin of this century, investigators all over the world have been reluctance at a century old procedure [1, 2] presently known as electrospinning. Likely unidentified to most investigators for most of the last century, electrospinning is able to develop uninterrupted fibers from the submicron diameter down to the nanometer diameter. It was not until the mid-1990s with concern in the area of nanotechnol-

\footnotetext{
*Corresponding Author: Kaleemullah Kalwar: Institute of Translational Medicine, Department of Pharmacology, Medical College, Yangzhou University, Yangzhou 225001, Jiangsu, China;

Email: Kalwar20@yahoo.com

Ming Shen: College of Chemistry and Chemical Engineering, Yangzhou University, Yangzhou 225002, Jiangsu Province, China; Email: shenming@yzu.edu.cn
}

ogy that investigators played to actualize the big potency of the procedure in nanofibers output [3]. Nanofibers with their large surface area to volume ratio, about a thousand times higher than that of a human hair, have the potency to significantly improve current engineering and find use in new fields. Uses of NFs include nanocatalysis, tissue scaffolds $[4,5]$, protective clothing, filtration and nanoelectronics [6]. The establishment of nanosize fibers via espinning is grounded on the uniaxial unfolding of a viscoelastic mixture. To empathize and appraise the procedure that alters the shaping of several nanofibers assemblies, the precepts of e-spinning and the dissimilar factors that involve the procedure have to be examined. Different formal fiber spinning techniques like dry-spinning and meltspinning, e-spinning builds function of electrostatic forces to stretch the solution as it solidifies. Alike to formal fiber spinning techniques, the drawing of the solution to make the fiber will proceed as long as there is enough solution to feed the electrospinning jet. Thus without any interruption to the electrospinning jet, the establishment of the fiber will be continuous.

Figure 1 (a) showing electrospinning process, typically there is 3 main elements to accomplish the procedure of electrospinning: 1) a high voltage supplier, 2) a capillary tube with the needle and 3) a collector. In this procedure, a high voltage is applied to produce an electrically charged jet of polymer solution. Ahead contacting the collector, the solution jet vaporizes, and is acquired as nanofibers [7]. One electrode is located into the spinning solution and other connected to the collecting area. The electric field is exposed to the end of the capillary tube that holds the polymer solution contained by its surface tension. This makes a charge on the overhead of the solution. Reciprocal charge repulsion and the compression of the overhead charges to the counter electrode cause a force straight inverse to the surface tension [8]. Likely strength of the electric area is raised, the hemispherical coat of the runny at the tip of the capillary tube stretches to form a cone-like form known as the Taylor cone. Moreover, raising the electric field, a critical value is achieved with which the repulsion electrostatic force defeats the surface tension and the charged jet of the

๑ Open Access. ( 2019 K. Kalwar and M. Shen, published by De Gruyter. (Cc) BY bution 4.0 License 


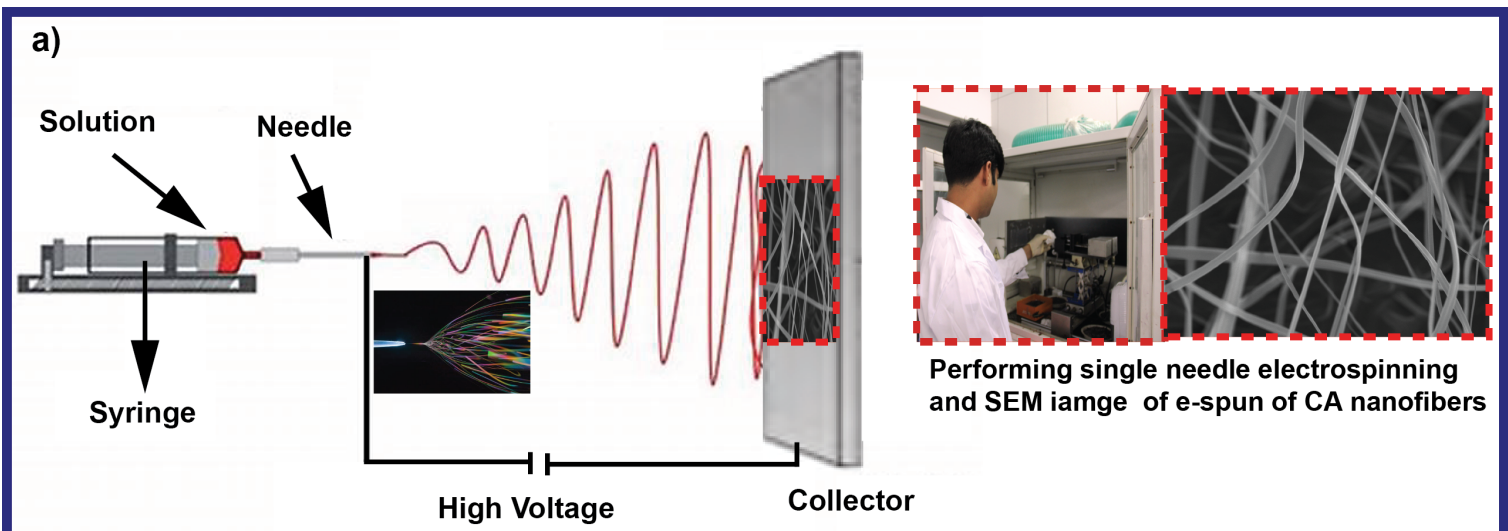

b)

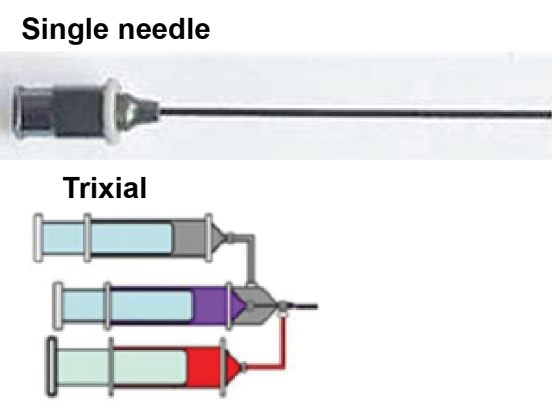

\section{Coaxial}

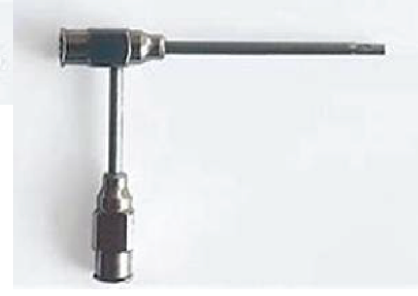

Multi-Coaxial

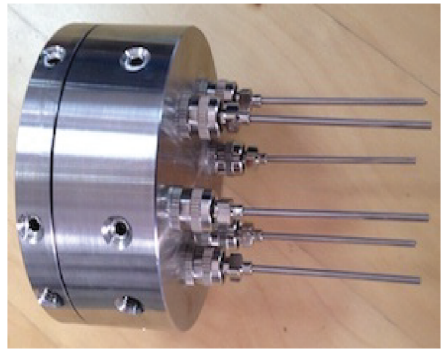

c)

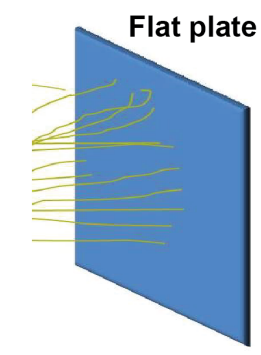

Coveyor

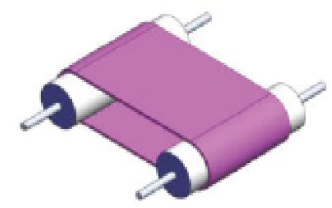

Multi-Needle
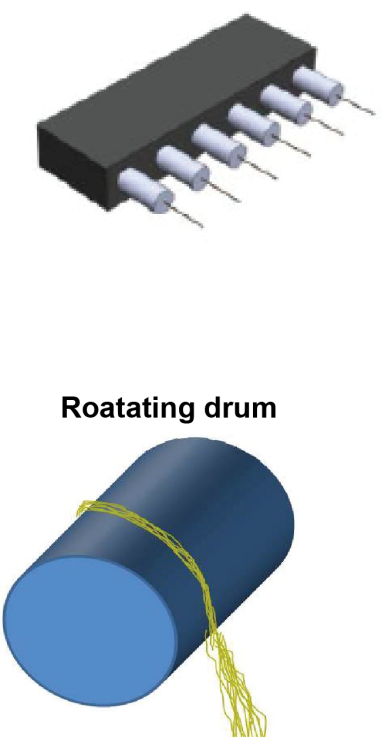

Roatating disc

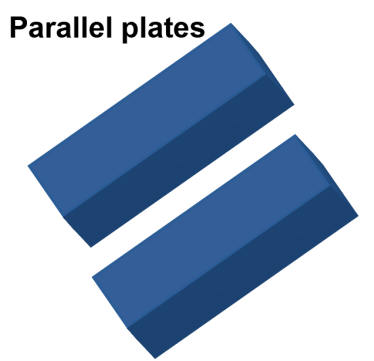

Roatating disc (sharp edges)

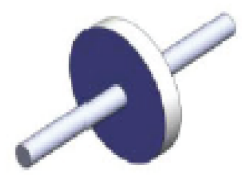

Multi-Needle

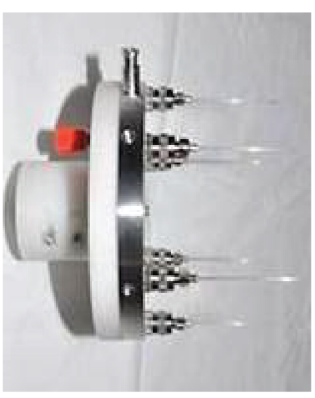


solution is released from the tip of the Taylor cone. The fired polymer fluid jet changes an unbalance and extension procedure, which permits the jet to turn very long and thin. The solvent vaporizes, allowing for a charged polymeric fabric.

Furthermore, particular changes to the fundamental experimental set-up have been established for developing the level of nano-fibers and for adjusting their possessions corresponding to demands of distinct uses. In fact, in horizon of prominent level output and of uses those obviously demonstrate important infomercial potency. The uniaxial placement of nano size fibers amongst the prescribed lay out is presented to be significant for various uses, therefore getting a significant requirement to be brought into importance in level high of the e-spun industry potentiality. In the area of tissue re-formation employed to muscles, bone and cartilage meniscus, and neural cells, different reports demonstrate that cell cultures on uniaxially aligned nano size fabrics scaffolds advantageous lengthen the nanofiber lengthwise axis [9]. The high volumes are particularly suitable for biomedical uses such as tissue engineering, design of wound healing, drug delivery, and for textile uses. In the theory of tissue engineering, e-spinning is especially desirable for the manufacturing of three dimensional composites afterward the concluding results accommodate almost of demands in conditions of substantial porousness (determined as the number of three dimensional, unsatisfied changes in the scaffolds, large surface area to volume ratio, and adjustable mechanical dimensions [10]. For wound curing or wound burn, e-spun, interconnected holey constructions are advantageous for exuding fluidize, restraining evacuation and helping oxygen permeation, and additionally, the flexibleness of the e-spinning procedure permits the accession of agents in the scaffolds, for health check discussion and antimicrobial uses. The concept to choose and right mix solution factors and line up their ratio to grants one to efficacy orient the attributes of e-spinning of nanofibers to get novel and in demand structures and practicalities.

\section{Cellulose acetate (CA) electrospun nanofibers}

CA is a easily obtainable substantial derived from cellulose at low cost and it is employed in the broad scope in sheets for food technology and medical applications because of its less perniciousness, good hydrolytic stability, and environmentally well-disposed attributes [11]. In addition, development in cellulose research demonstrates that it is an promising biological substance for tissue engineering, stem cell research, and regenerative medicine [12]. Bacterial cellulose is easily examined for bone regeneration. Thus, it doesn't propose the quality to assure the fabrics on the nano size or micro size, which bounds its pertinency in tissue engineering. Moreover, it is examined that, CA is easy in electrospinning as compared to cellulose. CA nanofibers can be easily converted from cellulose acetate to cellulose by alkaline hydrolysis; researching the many attributes of cellulose acetate in the nano size governing is a pertaining proposal. Within many, e-spinning has conferred a completely novel appearance to the uses of CA fibers or nanofibers. Previously reported by worldwide industriousness investigation, the global mart of CA is assigned to about $1.05 \mathrm{M}$ metric tons by 2017 (http://www. strategyr.com/Cellulose_Acetate_Market_Report.asp) and the main worldwide individuals regard Celanese Corporation, Daicel Corporation, Primester, Eastman Chemical Company amongst many. CA demonstrates a broad concept [13] evidencing its value in polymers investigation. The usual level of subtle of 2.45-2.5 discusses better solubility (in various kind of solvents) and meltability [14]. In previous report, it has directed extinct the environmental characteristic of CA situated fabrics evaluated in status of their biodegradability as a purpose of the synergy amongst different user consequences [15]. Lately, Group of Sousa have reported a dynamic work, concentrated on the subglass mobility in CA beneath geomorphic various constitutes [16]. Cellulose acetate NFs has relatively more modulus and enough angularity and tensile strength [17]. Conjoining with functional groups enables other concerning concept to cellulose acetate such as, surface modification with heavy metal ions [18]. Electrospun cellulose acetate nanofibers have experience a retentive journey and quaternary period conveys a exertions throughout the range of different fields. Herein, we have briefly discussed electrospinning of CA nanofibers for antimicrobial activity. Moreover, the effective and better handled purpose of e-spinning method should be modified for the structural fibers [19, 20]. Synthesized fibers have developed manysided uses in biomedical field [21-29]. Cellulose acetate has been studied due to its more beneficial characteristics which are; decomposable, compatible with biological tissue, not soluble in $\mathrm{H}_{2} \mathrm{O}$ etc. CA can be possibly employed for injure bandage and broadly employed for different form of possible exertions i-e germicide fibrous sheets, nanocomposites for biomedical uses etc [15, 30, 31]. 
Table 1: Parameters for electrospinning of cellulose acetate nanofibers

\begin{tabular}{|c|c|c|c|c|c|c|}
\hline $\begin{array}{c}\text { Solution } \\
\%\end{array}$ & Solvent & $\begin{array}{l}\text { Solvent } \\
\text { ratio }\end{array}$ & $\begin{array}{l}\text { Voltage } \\
\text { kV }\end{array}$ & $\begin{array}{l}\text { Distance } \\
\text { cm }\end{array}$ & Feed rate & Reference \\
\hline 17 & acetone/N,N-dimethylacetamide & $2: 1$ & 17.5 & $15 \mathrm{~cm}$ & $0.6 \mathrm{~mL} / \mathrm{h}$ & [48] \\
\hline 20 & acetone/N,N-dimethylacetamide & $2: 1$ & 8 & $\mathrm{~N} / \mathrm{A}$ & $12 \mathrm{~L} / \mathrm{min}$ & [49] \\
\hline $13,19,25$ & acetone/N,N-dimethylacetamide & $3: 1: 5$ & 18 & 16 & $1 \mathrm{~mL} / \mathrm{h}$ & {$[50,51]$} \\
\hline $\begin{array}{l}6,8,10 \\
12\end{array}$ & $\begin{array}{l}\text { 4,40-diphenylmethane } \\
\text { Diisocyanate/acetone }\end{array}$ & $1: 2$ & 20 & 17 & $0.5 \mathrm{~mL} / \mathrm{h}$ & [52] \\
\hline 18 & Acetone/ N,N-dimethylformamide & $3: 2$ & 12 & 15 & $\mathrm{~N} / \mathrm{A}$ & [53] \\
\hline 15 & Acetone/ N,N-dimethylformamide & $3: 2$ & 18 & 16 & $1 \mathrm{~mL} / \mathrm{h}$ & {$[54]$} \\
\hline 17 & acetone/N,N-dimethylacetamide & $2: 1$ & 17 & 15 & $1 \mathrm{~mL} / \mathrm{h}$ & {$[55]$} \\
\hline 10 & acetone/Polyethylene oxide- & - & - & - & - & [56] \\
\hline 20 & $\mathrm{~N}, \mathrm{~N}$-dimethyl Acetamide/ dimethyl sulfoxide & $\mathrm{N} / \mathrm{A}$ & $\mathrm{N} / \mathrm{A}$ & $\mathrm{N} / \mathrm{A}$ & $\mathrm{N} / \mathrm{A}$ & {$[57]$} \\
\hline 20 & N-Ndimethyl formamide & - & 25 & 20 & $0.5 \mathrm{~mm}$ & {$[58]$} \\
\hline 20 & acetone/N,N-dimethylacetamide & $2: 1$ & 16 & 16 & $\begin{array}{c}0.02 \\
\mathrm{~mL} / \mathrm{min}\end{array}$ & [59] \\
\hline 13 & acetone/N,N-dimethylacetamide & $2: 1$ & 25 & 25 & $3 \mathrm{~mL} / \mathrm{h}$ & {$[60]$} \\
\hline 15 & acetone/N,N-dimethylacetamide & $2: 1$ & 14.25 & 25 & $1 \mathrm{~mL} / \mathrm{h}$ & [61] \\
\hline 17 & acetone/N,N-dimethylacetamide & $2: 1$ & 25 & 25 & $1 \mathrm{~mL} / \mathrm{h}$ & {$[62]$} \\
\hline 12.5 & acetone/N,N-dimethylacetamide & $2: 1$ & 20 & 20 & $1 \mathrm{~mL} / \mathrm{h}$ & {$[63]$} \\
\hline 12 & dichloromethane/methanol & $4: 1$ & 15 & 10 & $1 \mathrm{~mL} / \mathrm{h}$ & {$[64]$} \\
\hline 15 & acetone & - & - & 15 & $\begin{array}{l}3 \text { or } 5 \\
\mathrm{~mL} / \mathrm{h}\end{array}$ & {$[65]$} \\
\hline $\begin{array}{c}9,11,13 \\
15\end{array}$ & Acetone/water & $\begin{array}{l}80: 20 \\
90: 10\end{array}$ & $12-15$ & $20-22$ & $\begin{array}{l}2 \text { to } 4 \\
\mathrm{~mL} / \mathrm{h} .\end{array}$ & {$[66]$} \\
\hline
\end{tabular}

\subsection{Choice of solvent for cellulose acetate e-spun nanofabrication}

In 1934 [32], Formhals tried the e-spinning of cellulose acetate nanofibers by utilizing acetone as the solvent. CA nanofibers have been synthesized by using different conditions Table 1. Here we are describing selection of solvent for CA electrospinning. The solvent choice is important and has been conventionally grounded on contest and occurrence, outcomes of solvability methods set by physical chemical database [33]. The phenomenons of different solvent schemes on the morphology and size of nanofibers have been examined [3439]. The single solvent system contained of acetone, chloroform, N, N-dimethylformamide, dichloromethane, formic acid, and methanol $(\mathrm{MeOH})$ and pyridine. Acetonedimethylacetamide (DMAc), chloroform- $\mathrm{MeOH}$, and $\mathrm{DCM}-\mathrm{MeOH}$ were amongst the combined solvent systems. The deformation viscousness, surface tension, and conductibility of these solvent systems have been assessed to be vital solution arguments in producing smooth nanofibers. However, three solvent system of acetone/DMF/trifluro-ethanol has also been assessed for e-spinning CA [40]. The property version of a mixed solvent system of acetic acid/water has been determined to prescribe the size allocation of the electrospinning of cellulose acetate [41]. CA based electrospun fibers in existence of poly(ethyleneglycol), poly(ethylene oxide) and hydroxyapatite have been evaluated applying DMAc/acetone, DMF, DMF/dioxane and acetic acid/acetone systems [42]. An important remark was sent on by Haas and co-workers concerning the function of solvent excitableness in restraining the appeared coordinate of cellulose acetate fiber [33]. The Hansen's method of solvability tells us to choose atoxic binary systems, improvement for production of cellulose e-spun nanofibers systems with adaptable level of fibers merger deserves limited remark in the circumstance of eco-friendly nanotech. Good packaging property was acquired with two less volatile mixture solvent. Ribbon like structure was observed for cellulose nanofibers produced from binary solvent system and achieved cylindrical shape [43]. Few studies are acquirable on the consequence of close arguments and e-spinning arguments on the quality of CA e-spun nanofibers. Humidity has influence on size of CA fibers, average size of diameter increased by increasing humidity. Besides, temperature 
prescribes the solvent drying up rate and viciousness of the mixture. Humidity and temperature were discovered to have fundamental effect on the size of cellulose acetate nanofibers [44]. The phenomenon of various factors considering field strength, space between tip to collector, feed rate of solution and property on the structure of CA e-spun nanofibers are previously reported [45]. Some determined parameters can be modified by using Box-Behnken pattern method for CA electropsun fibers [30]. Structure and fibers diameter were determined to be affected by High power, space between needle tip to collector and feed rate of the polymer solution made in acetic acid/water mixture solvent. Concern for CA electrospinning fibers as blends and pure has been increasing in last decay. CA has been blend electorspun with natural polymers and nanomaterials such as AgNPs etc. Studying to cellulose, cellulose CA has better dissolvableness therefore, different solvents system are available [30, 46, 47].

\subsection{Electrospun cellulose acetate nanofibers with AgNPs for antimicrobial activity}

The destructive effects of antimicrobial are already manifesting themselves across the globe. Several disinfectant substances have been formulated for healing and keeping illnesses in public health medicine and antigen in biomedical diligence [11, 12, 67, 68]. A very important aspect of nanomaterials action on bacterial cells, which must be considered when discussing the inhibitory effect of it tested on different types of microorganisms. Bacteria are commonly classified into Gram positive and Gram negative, depending on their cell walls. Gram positive bacteria have an extra thick peptidoglycan layer on the outer surface, while Gram negative bacteria have an outer membrane behind which a thin peptidoglycan layer exists. This drastic difference in the nature of the cell boundaries is a great challenge for having a general antibacterial material against the bacteria [69]. Biological active substances, considering sutures, implants (such as vascular prostheses, prosthetic heart valves, ureteral stents, and hernia meshes), and composites, gestate the adventure of infections at operative position, those are basic interest of hospital borrowed infections. The synthesis of nanofibers containing metal NPs is well explored due to vantages required with mixing the functional attributes of metal nanoparticles with the broadly relevant ownerships of nano size fibers. Metal carrying e-spun nano size fibers have tugged concern as a new shape of antimicrobic matter. Ag is a broadly employed and distinguished wide spectrum antimicrobial substance which is good ver- sus bacteria, fungi, and viruses but is nontoxic to mammalian cell. In addition, sequence of the high level, particular overhead side and thinness of e-spun nano size fibers with the antimicrobial effect of metal NPs outcomes in an excellent and various disinfectant substance. Materials based on cellulose like CA are a particularly good choice for preparing these materials, due to their excellent performance characteristics; CA, for example, exhibits good toughness, high biocompatibility, and relatively low cost. Moreover, the cellulose explores demonstrates, a predicting promising biological substance for tissue engineering, stem cell research, and regenerative medicine [70]. Cellulose produced by bacteria is merely examined for bone reclamation [71-73]. Therefore, it doesn't provide the quality to assure the fibers on the nano and micro size, it confines applicability of cellulose nano or micro size fibers for tissue engineering. CA is easy to electrospun. Besides, CA nanofibers can be easily deacetylated to cellulose by alkaline hydrolysis [74]. Furthermore, a number of antimicrobial agents or antibiotics can be comprised of nanofibers for the prevention of microbial infection $[75,76]$. In this part, we will briefly discuss the effect of cellulose nanofibers with AgNPs on antimicrobials. Cellulose acetate nanocomposite was determined to have able of inhibiting the growth of infective micro-organism [77, 78]. Numbers of reports are available on cellulosic based material [34-36, 38, 41, 49-52, 79-85]. Antimicrobial agents of cellulose acetate such as AgNPs and ZnNPs have been reported recently [30]. It has been reported that the synthesis of e-spun CANFs surface coated with AgNPs [86]. Apart, interceded in place chemical reaction of metal salts for the synthesis of NPs coated cellulose acetate nanofibers [87, 88]. Before elevating CA/AgNPs, it would be fruitful to discuss basic of silver nanoparticles. Within many types of bactericide stuffs, investigators are progressively becoming to nano-size materials because of specific sequence of physio-chemical concepts. Those nano-size materials have been studied in different areas, like drug delivery and imaging [89-95]. Specifically, investigators have studied the attributes of nanomaterials like $\mathrm{Ag}, \mathrm{Au}, \mathrm{Zn}$, and $\mathrm{Cu}$ [96-99]. From these nanomaterials, AgNPs have evidenced fantabulous bactericide effect [100]. Moreover, toxicity mechanism of AgNPs has been previously studied. Up to date the report is available on biomedical application of AgNPs [101]. Incorporation of silver nanoparticles cellulose substratum to carry out bactericide effect has also been recognized [102].

Furthermore, the high dose of AgNPs also elicits wellness and bionomical involvements. The termination of AgNPs in $\mathrm{H}_{2} \mathrm{O}$ creates the stuff to easy break up into ions few days, and toxic conditions for cell enhance with the 


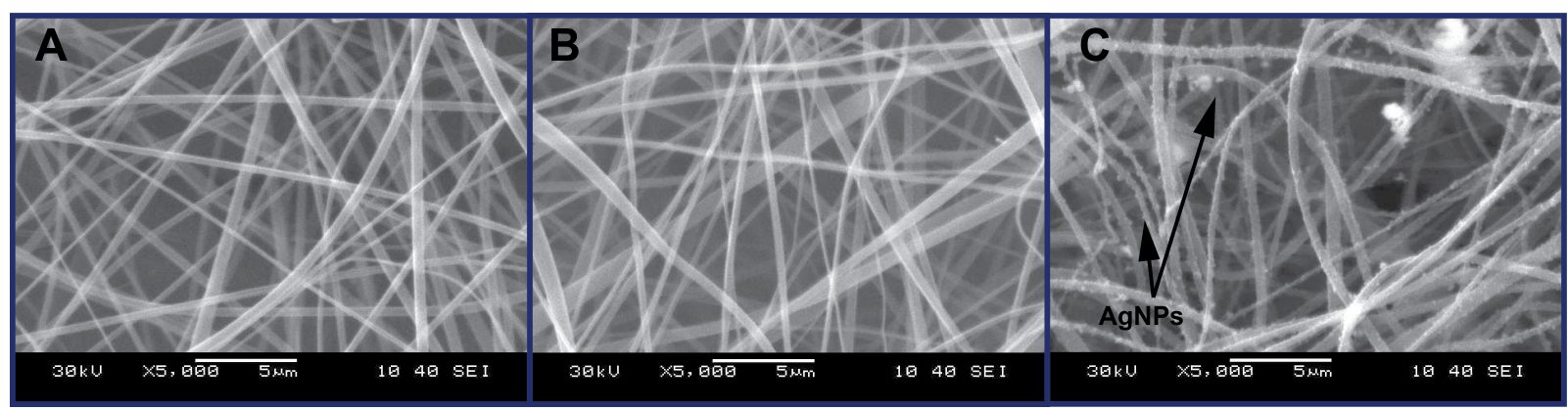

Figure 2: SEM Images of a) Cellulose acetate nanofibers b) Regenerated cellulose nanofibers c) AgNPs incorporated cellulose nanofibers [51]

amount of $\mathrm{Ag}^{+}$in the distribution. Some study demonstrated AgNPs are supposed of exposing harm for mammalian cells $[96,103,104]$. Still, although there being many infomercial products are available which flick AgNPs to control bacteria to handle cuts, scrapes, and burns, it is significant to formulate novel stuff which exhibit less perniciousness and more biocompatibility to develop bactericide profile which should be secure for mammalian cell and the ecosystem. Moreover, $\mathrm{Ag}$ also has been studied with $\mathrm{Au}$ for improving its properties such as antimicrobial effect and non toxicity for mammalian cell. Though Ag@AuNPs core and shell nanoparticles have been synthesized this can show better results for biomedical applications. However, Only AgNPs are depicted harmful for mammalian cell in high dose; combination of noble metals would be a better choice for biomedical applications such as Ag@Au and Au@Pt [105, 106].

Additionally, Silver nanoparticles decorated in polymeric substrata can empower the complexes with convenient optical attributes and increased bactericide effects [107-110]. That stuff has been employed in broad biomedical applications [111-113]. Due to bactericide action of Ag-based materials have been demonstrated powerfully believe in their property such as size and shape [114]. Cellulose based material is more attractive for Ag-Based nanocomposite due to its surface functional groups $(\mathrm{OH})$ which is electron rich characteristic. Though, it has effective colloidal steadiness in aqueous solution. Incorporation of nanoparticles can be restrained by the H-bond system that is organized by the hydroxyl groups in the morphology of cellulose. Aforementioned, as compared with cellulose, cellulose acetate can be easily electrospun, it can be regenerated as cellulose nanofibers by alkaline hydrolysis. Recently cellulose acetate is used for electrospun and then AgNPs incorporated by chemical reduction method. Cellulosic NFs were produced by alkaline hydrolysis from cellulose acetate nanofibers. Cellulose acetate nanofibers were synthesized by e-spun method, various concentration of CA solution was synthesized in solution of 2:1.5 N,N-dimethylacetamide DMAc and acetone (v/v) and cellulose acetate and cellulose nanofibers structure were found smooth at $25 \%$ solution of cellulose acetate Figure 2A [50,51]. Figure 2B is showing cellulose regenerated electrospun nanofibers. After deacetylation, there was a little change in size of nanofibers. Regenerated cellulose nanofibers were decorated by AgNPs this can be seen in Figure 2C. Cellulose nanofibers with AgNPs have bactericide effects and the physiochemical properties of AgNPs have an impression on antibacterial activity Figure 5B. Moreover, AgNPs with excessive amount has better results than lower concentration. Cellulose acetate is definitely a good choice for electrospun nanofibers for biomedical applications by combining with nanomaterials. Electrospun cellulose acetate nanofibers in combination with Ag@Au core and shell could be a good choice for biomedical applications. Recently different size of Ag@Au NPs core shell decorated on cellulose paper has been prepared by Tsai et al for antibacterial activity. It was postulated that $\mathrm{Au}$ NPs works as core and AgNPs as shell [115]. Cellulose paper directly has been directly used for Au@AgNPs decoration Figure 3. It is presented that Au-Ag100/1 and Au-Ag1000/1 NP-coated cellulose paper can inhibit E. coli, with $15 \mathrm{~nm}$ $\mathrm{Au}-\mathrm{Ag} 100 / 1 \mathrm{NPs}$ demonstrated the firmest antibacterial activity. Figure 4 showing antibacterial effect of different size Au@AuNPs/cellulose. Moreover, it can be suggested that the silver coating is creditworthy for the bactericide activity, nearly because of the action of silver ions from the coat of the Au@AgNPs.

\section{Silver nanoparticles (AgNPs) properties}

Silver nanoparticles breaking consequence on the bacterial membrane could be powerfully associated with 

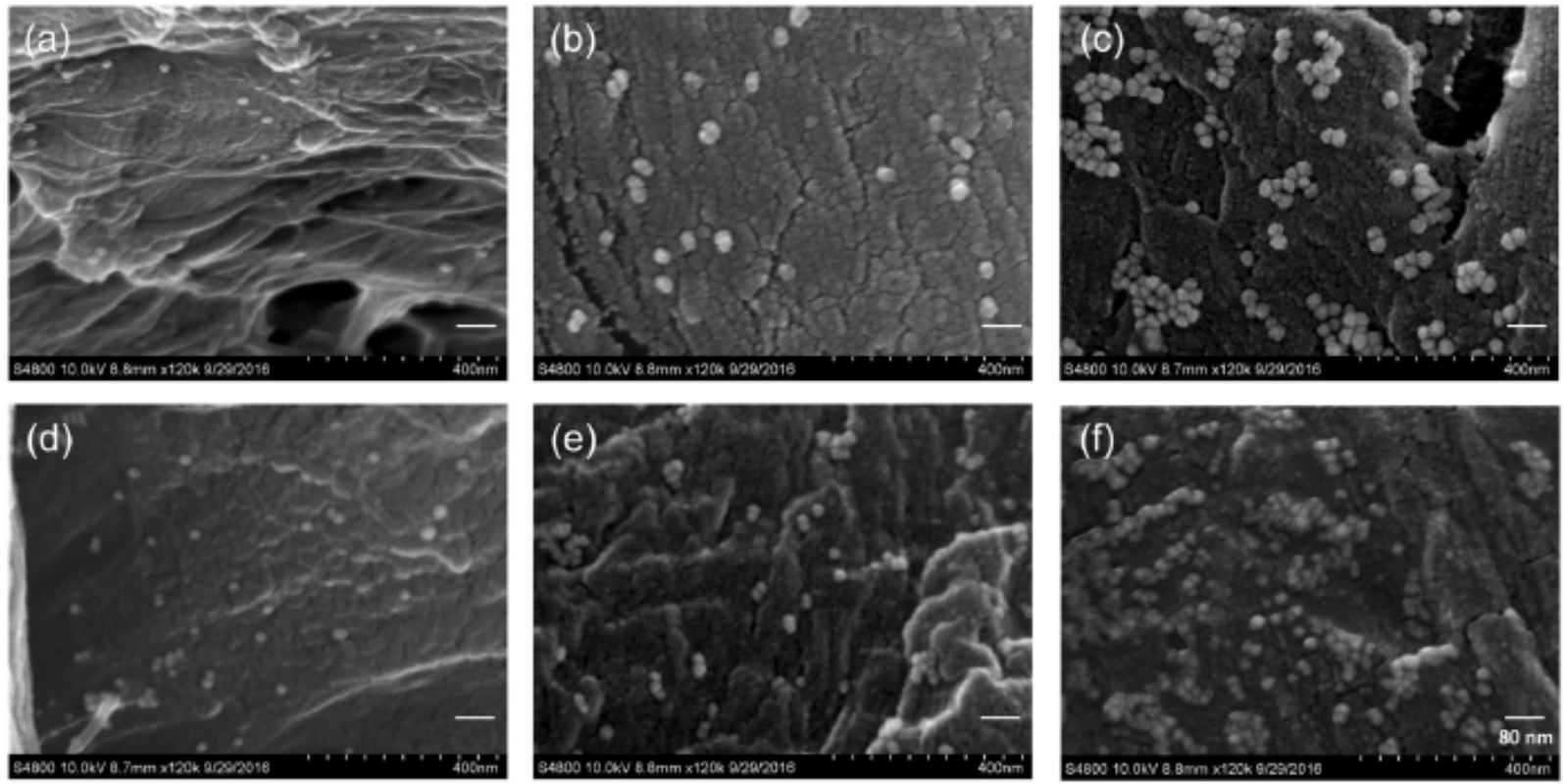

Figure 3: SEM images of the dissimilar Au and Au@AgNPs on cellulose paper. (a) 20 nm AuNPs, (b) 20 nm Au@AgNPs 1000/1, (c) 20 nm Au@AgNPs100/1, (d) 15 nm AuNPs, (e) 15 nm Au@AgNPs1000/1, and (f) 15 nm Au@AgNPs100/1 [115]

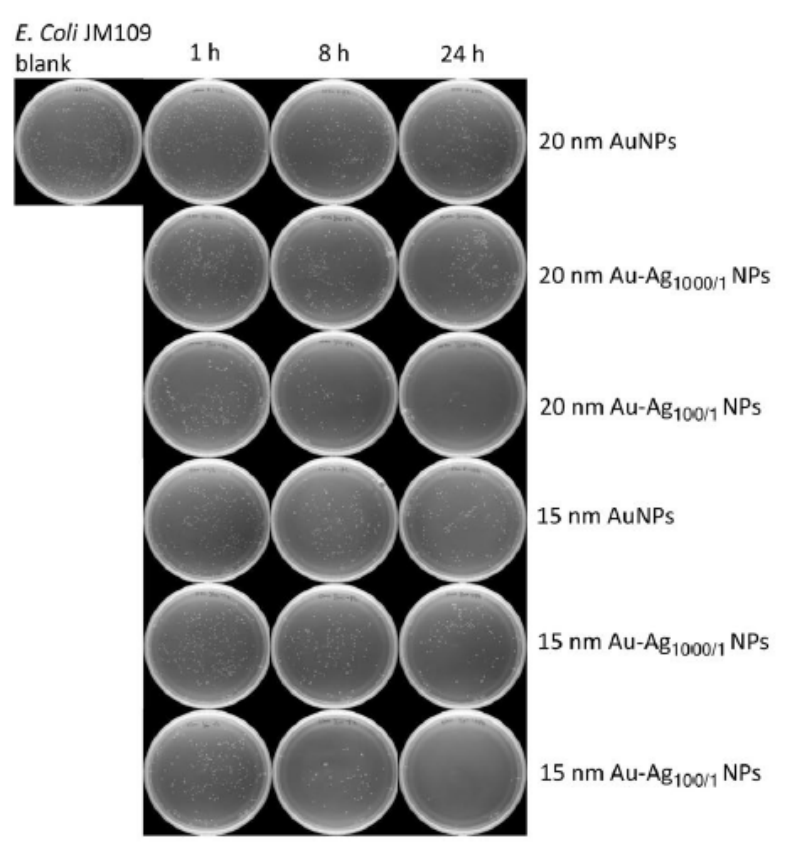

Figure 4: The antibacterial activity of dissimilar Au and Au@AgNPs against E. coli [115]. (Published in Scientific Reports)

their physical and chemical properties, such as size and shape [116, 117]. The primary requirement for AgNPs to cause the membrane impairment is the capability to act with the bacteria membrane. Size of the nanoparticles is significant expressions in influencing their action with membranes. Small size NPs would amend interaction with the bacterial cells as studied to the same dose of their bigger size NPs. 1-10 nm in diameter were determined to be the most efficient in inhibiting to the bacterial cell due to their discriminatory directly action with the cell membrane [118]. Additionally, the smallest AgNPs demonstrated the most eminent antimicrobic effeteness and rapid bacterial inhibiting activity [119]. Electrospun Cellulose acetate nanofibers decorated with different size of AgNPs were studied. Figure 5a showing TEM images of AgNPs decorated cellulose nanofibers and inhibition effete of different size AgNPs on E. coli can be seen in Figure 5b. $14 \mathrm{~mm}$ and $11.9 \mathrm{~mm}$ zone inhibition activity has been found from two different sizes AgNPs.

Polyvinylpyrrolidone decorated silver nanoparticles with unlike forms proposes a stats between the shape of AgNPs for antimicrobial properties. Two dimensional Ag nanoplates possess higher germicide toward $\mathrm{S}$. aureus and E. coli when examined to one dimensional Ag nanorods and round AgNPs zero dimensional morphology. It was claimed that Ag nanoplates contain the larger surface area, which could provide higher interaction with bacterial cell [120]. Moreover, the shape of nanoparticles also can affect Ag atoms dispersion [121]. Silver ions are responsible for killing or inhibiting microbes. The oxidation states of AgNPs assuming when desig of antimicrobial AgNPs. It was less toxic towards E. coli as compared to the $\mathrm{Ag}^{+}$ions in an aerobic place. The lack of $\mathrm{Ag}$ oxidation was responsible for less antimicrobial activity, suggesting the value of silver ion in the antimicrobic activity of $\mathrm{Ag}$ - 


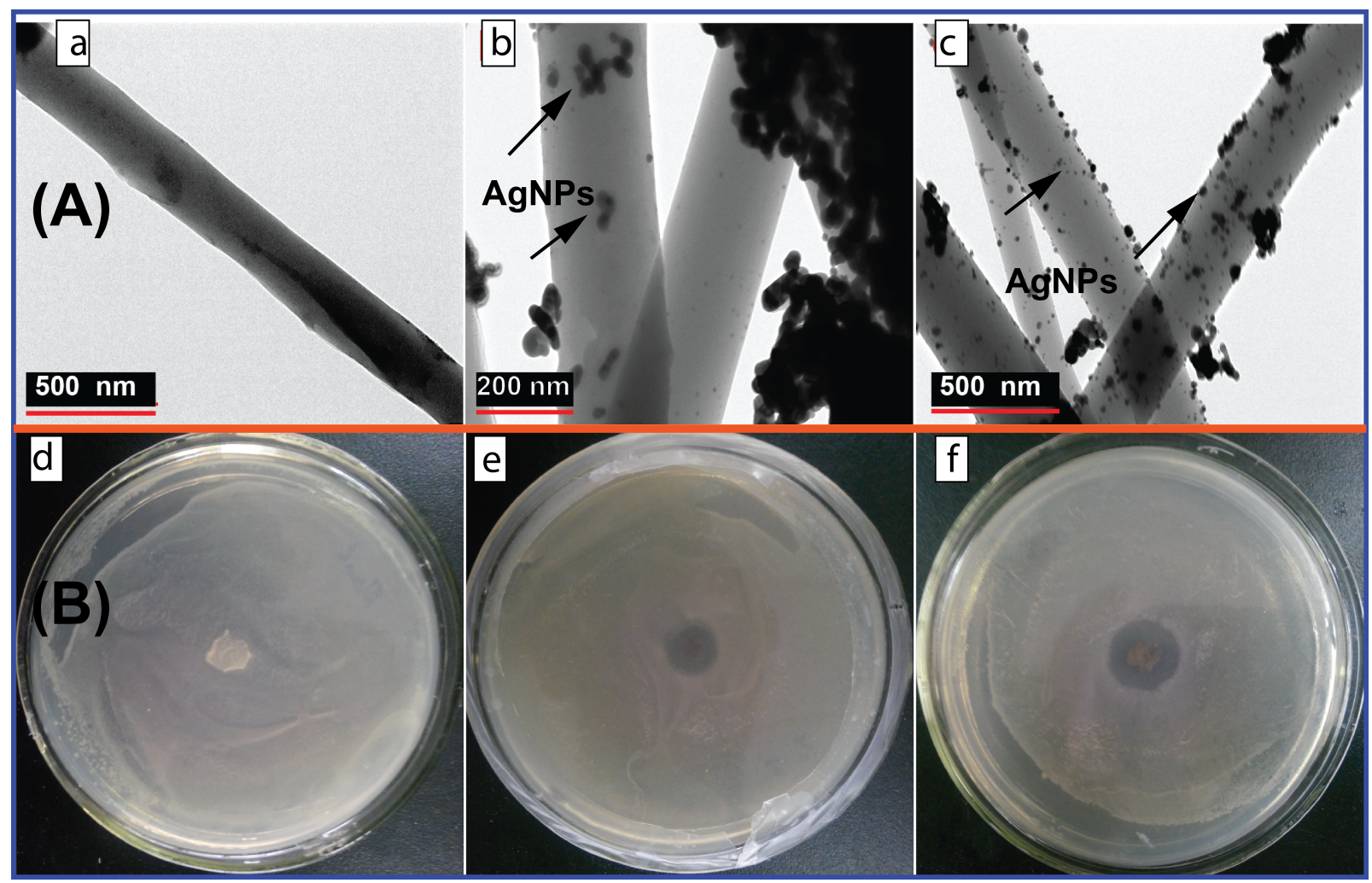

Figure 5: A) demonstrating TEM images of a) regenerated cellulose nanofibers b\&c), regenerated cellulose nanofibers with AgNPs decoration (42.33 nm and $16.69 \mathrm{~nm}$ ); B) demonstrating antibacterial activity of AgNPs against E. coli d) regenerated cellulose nanofibers e\&f) regenerated cellulose nanofibers with AgNPs decoration (42.33 nm and $16.69 \mathrm{~nm}$ ) [50]

NPs [122]. Partially oxidized AgNPs can have somehow antimicrobic effect, but zero valent AgNPs may not. Aforementioned, suggesting the quantity of chemical-sorbed silver ion on the cover of silver nanoparticles would influence the maintained antimicrobic activity [123]. Silver ions possible inhibition mechanism for microbes are $\mathrm{Ag}^{+}$controls Adenosine triphosphate (ATP) production through attaching to the ATP synthesis enzyme in the cell wall, it enters into the cell wall and attaches to DNA which leads to the DNA alteration or these ions with the nucleus of the cell.

\section{Conclusions}

For the application of cellulose acetate nanofibers, electrospinning technique has presented a completely modern orientation. CA has been considered for electrospun nanofibers because of decomposable, biocompatible, and not soluble in water. In addition, the selection of solvent, decently mix solution factors and settle their ratio which effectively reserves the attributes of nanofibers synthesized by e-spinning technique. Moreover, for the cellulose acetate, acetone/dimethylacetamide found bet- ter solvent during electrospinning. Aforementioned, CA nanofibers can be possibly employed for antimicrobial activity and wound dressing. However, cellulose acetate nanofibers can easily be deacetylated by alkaline hydrolysis. Cellulose nanofibers were decorated with different concentration and size of AgNPs for antimicrobial effect. A nanoparticle with smaller size possesses higher antimicrobial activity because it can directly interact with the cell. Combination of metal with electrospun cellulose acetate nanofibers could make a great contribution to biomedical application.Au@Ag bimetallic nonmaterial with electrospun nanofibers could be used for biomedical applications.

Acknowledgement: This research was supported by National Natural Science Foundation of China (Grant No. 81671810 and No. 21673201).

\section{References}

[1] Cooley J.F., Apparatus for electrically dispersing fluids, 1902, Google Patents. 
[2] Morton W.J., Method of dispersing fluids, 1902, Google Patents.

[3] Doshi J., Reneker D.H., Electrospinning process and applications of electrospun fibers, J. Electrostat., 1995, 35, 151-60.

[4] Li W.J., Laurencin C.T., Caterson E.J., Tuan R.S., Ko F.K., Electrospun nanofibrous structure, a novel scaffold for tissue engineering, J. Biomed. Mater. Res., 2002, 60, 613-21.

[5] Wang Y.K., Yong T., Ramakrishna S., Nanofibres and their influence on cells for tissue regeneration, Aus. J. Chem., 2005, 58, 704-12.

[6] Ramakrishna S., An introduction to electrospinning and nanofibers, World Scient., 2005.

[7] Deitzel J., Kleinmeyer J., Hirvonen J., Tan N.B., Controlled deposition of electrospun poly (ethylene oxide) fibers. Polym., 2001, 42, 8163-70.

[8] Fang X., Reneker D., DNA fibers by electrospinning. J. Macromol. Sci., Phys., 1997, 36, 169-73.

[9] Baker S.C., Atkin N., Gunning P.A., Granville N., Wilson K., Wilson D., Southgate J., Characterisation of electrospun polystyrene scaffolds for three-dimensional in vitro biological studies. Biomater., 2006, 27, 3136-46.

[10] Chew S.Y., Hufnagel T.C., Lim C.T., Leong K.W., Mechanical properties of single electrospun drug-encapsulated nanofibres. Nanotechnol., 2006, 17, 3880.

[11] Fuchs A.D., Tiller J.C., Contact-active antimicrobial coatings derived from aqueous suspensions. Ang. Chemie Int. Ed., 2006, 45, 6759-62.

[12] Kurt P., Wood L., Ohman D.E., Wynne K.J., Highly effective contact antimicrobial surfaces via polymer surface modifiers, Langmuir, 2007, 23, 4719-23.

[13] Edgar K.J., Cellulose esters, organic, Encyclopedia of polymer science and technology, 2002.

[14] Fischer S., Thümmler K., Volkert B., Hettrich K., Schmidt I., Fischer K., Properties and applications of cellulose acetate, Macromol. Symp., 2008, 89-96, Wiley Online Library.

[15] Puls J., Wilson S.A., Hölter D., Degradation of cellulose acetatebased materials, a review, J Polym. Environ., 2011, 19, 152-65.

[16] Sousa M., Bras A.R., Veiga H.I.M., Ferreira F.C., de Pinho M.N., Correia N.T., Dioniśio M., Dynamical characterization of a cellulose acetate polysaccharide, J. Phys. Chem., 2010, 114, 10939-53.

[17] Aoki D., Teramoto Y., Nishio Y., SH-containing cellulose acetate derivatives, preparation and characterization as a shape memory-recovery material, Biomacromol., 2007, 8, 3749-57.

[18] Liu C., Bai R., Adsorptive removal of copper ions with highly porous chitosan/cellulose acetate blend hollow fiber membranes, J. Membr. Sci., 2006, 284, 313-22.

[19] Baharifar H., Honarvarfard E., Haji Malek-kheili M., Maleki H., Barkhi M., Ghasemzadeh A., Khoshnevisan K., The Potentials and Applications of Cellulose Acetate in biosensor technology, Nanomed. Res. J., 2017, 2, 216-23.

[20] Samadian H., Salehi M., Farzamfar S., Vaez A., Ehterami A., Sahrapeyma H., Goodarzi A., Ghorbani S., In vitro and in vivo evaluation of electrospun cellulose acetate/gelatin/hydroxyapatite nanocomposite mats for wound dressing applications. Artificial cells, Nanomed. Biotechnol., 2018, 1-11.

[21] Boroumand S., Hosseini S., Salehi M., Faridi Majidi R., Drugloaded electrospun nanofibrous sheets as barriers against postsurgical adhesions in mice model, Nanomed. Res. J., 2017, 2, 64-72.

[22] Farzamfar S., Naseri-Nosar M., Vaez A., Esmaeilpour F., Ehterami A., Sahrapeyma H., Hamidieh A. A., Ghorbani S., Goodarzi A.,
Azimi A., Neural tissue regeneration by a gabapentin-loaded cellulose acetate/gelatin wet-electrospun scaffold. Cellulose, 2018, 25, 1229-38.

[23] Gheibi A., Khoshnevisan K., Ketabchi N., Derakhshan M.A., Babadi A.A., Application of Electrospun Nanofibrous PHBV Scaffold in Neural Graft and Regeneration, A Mini-Review, Nanomed. Res. J., 2016,1, 107-11.

[24] Khalf A., Madihally S.V., Recent advances in multiaxial electrospinning for drug delivery, Europ. J. Pharmac. Biopharmac., 2017, 112, 1-17.

[25] Li W., Li X., Wang T., Li X., Pan S., Deng H., Nanofibrous mats layer-by-layer assembled via electrospun cellulose acetate and electrosprayed chitosan for cell culture, Eur. Polym. J., 2012, 48, 1846-53.

[26] Sadri M., Mohammadi A., Hosseini H., Drug release rate and kinetic investigation of composite polymeric nanofibers, Nanomed. Res. J., 2016, 1, 112-21.

[27] Samadian H., Mobasheri H., Hasanpour S., Faridi Majidi R., Electrospinning of polyacrylonitrile nanofibers and simulation of electric field via finite element method, Nanomed. Res. J., 2017, 2, 87-92.

[28] Samadian H., Mobasheri H., Hasanpour S., Majid R.F, Needleless electrospinning system, an efficient platform to fabricate carbon nanofibers, Trans. Tech. Publ., 2017, 78-89.

[29] Sperling L.E., Reis K.P., Pranke P., Wendorff J.H., Advantages and challenges offered by biofunctional core-shell fiber systems for tissue engineering and drug delivery, Drug Discov. Today, 2016, 21, 1243-56.

[30] Konwarh R., Karak N., Misra M., Electrospun cellulose acetate nanofibers, the present status and gamut of biotechnological applications, Biotechnol. Adv., 2013, 31, 421-37.

[31] Li W., Li T., Li G., An L., Li F., Zhang Z, Electrospun H4SiW12040/cellulose acetate composite nanofibrous membrane for photocatalytic degradation of tetracycline and methyl orange with different mechanism, Carbohyd. Polym., 2017, 168, 153-62.

[32] Formhals A., Process and apparatus for preparing artificial threads, US Patent No 1,975,504, 1934.

[33] Haas D., Heinrich S., Greil P., Solvent control of cellulose acetate nanofibre felt structure produced by electrospinning, J. Mater. Sci., 2010, 45, 1299-306.

[34] Tungprapa S., Puangparn T., Weerasombut M., Jangchud I., Fakum P., Semongkhol S., Meechaisue C., Supaphol P, Electrospun cellulose acetate fibers, effect of solvent system on morphology and fiber diameter, Cellulose, 2007, 14, 563-75.

[35] Liu H., Hsieh Y.L., Ultrafine fibrous cellulose membranes from electrospinning of cellulose acetate, J, Polym. Sci., 2002, 40, 2119-29.

[36] Liu H., Tang C., Electrospinning of cellulose acetate in solvent mixture N, N-dimethylacetamide (DMAc)/acetone, Polym. J, 2007, $39,65$.

[37] Ma Z., Kotaki M., Ramakrishna S., Electrospun cellulose nanofiber as affinity membrane, J. Membrane Sci., 2005, 265, 115-23.

[38] Son W.K., Youk J.H., Lee T.S., Park W.H., Electrospinning of ultrafine cellulose acetate fibers, studies of a new solvent system and deacetylation of ultrafine cellulose acetate fibers, J. Polym. Sci., 2004, 42, 5-11.

[39] Zhou W., He J., Cui S., Gao W., Studies of electrospun cellulose acetate nanofibrous membranes, Open Mater. Sci. J., 2011, 5. 
[40] Ma Z., Ramakrishna S.. Electrospun regenerated cellulose nanofiber affinity membrane functionalized with protein $A / G$ for IgG purification, J. Membr. Sci., 2008, 319, 23-8.

[41] Han S.O., Youk J.H., Min K.D., Kang Y.O., Park W.H., Electrospinning of cellulose acetate nanofibers using a mixed solvent of acetic acid/water, Effects of solvent composition on the fiber diameter, Mater. Lett., 2008, 62, 759-762.

[42] Lee K.Y., Jeong L., Kang Y.O., Lee S.J., Park W.H., Electrospinning of polysaccharides for regenerative medicine, Adv. Drug Deliv. Rev, 2009, 61, 1020-32.

[43] Rodríguez K., Gatenholm P., Renneckar S., Electrospinning cellulosic nanofibers for biomedical applications, structure and in vitro biocompatibility, Cellulose, 2012, 19, 1583-98.

[44] De Vrieze S., Van Camp T., Nelvig A., Hagström B., Westbroek P., De Clerck K., The effect of temperature and humidity on electrospinning, J. Mater. Sci., 2009, 44, 1357.

[45] Christoforou T., Doumanidis C., Biodegradable cellulose acetate nanofiber fabrication via electrospinning, J. Nanosci. Nanotechnol., 2010, 10, 6226-33.

[46] Omollo E., Zhang C., Mwasiagi J.I., Ncube S., Electrospinning cellulose acetate nanofibers and a study of their possible use in high-efficiency filtration, J.Indust. Text., 2016, 45, 716-29.

[47] Wu S., Qin X., Li M., The structure and properties of cellulose acetate materials, a comparative study on electrospun membranes and casted films, J. Indust. Text., 2014, 44, 85-98.

[48] Rojanarata T., Plianwong S., Su-uta K., Opanasopit P., Ngawhirunpat T., Electrospun cellulose acetate nanofibers as thin layer chromatographic media for eco-friendly screening of steroids adulterated in traditional medicine and nutraceutical products, Talant, 2013, 115, 208-13.

[49] Li K., Wang J., Liu X., Xiong X., Liu H., Biomimetic growth of hydroxyapatite on phosphorylated electrospun cellulose nanofibers, Carbohyd. Polym., 2012, 90, 1573-81.

[50] Kalwar K., Bhutto M.A., Dali L., Shan D., Cellulose based nanofabrication: immobilization of silver nanoparticales and its size effect against Escherichia coli, Mater. Res. Exp., 2017, 4, 105405.

[51] Kalwar K., Hu L., Li D.L., Shan D., AgNPs incorporated on deacetylated electrospun cellulose nanofibers and their effect on the antimicrobial activity, Polym. Adv.Technol., 2018, 29, 394-400.

[52] Li R., Jiang Q., Ren X., Xie Z., Huang T.S., Electrospun nonleaching biocombatible antimicrobial cellulose acetate nanofibrous mats, J. Indust. Eng. Chem., 2015, 27, 315-21.

[53] Hamano F., Seki H., Ke M., Gopiraman M., Lim C.T., Kim I.S., Cellulose acetate nanofiber mat with honeycomb-like surface structure, Mater. Lett., 2016, 169, 33-6.

[54] Fu J., Li D., Li G., Huang F., Wei Q., Carboxymethyl cellulose assisted immobilization of silver nanoparticles onto cellulose nanofibers for the detection of catechol, J. Electroanalyt. Chem. 2015, 738, 92-9.

[55] Joshi M.K., Tiwari A.P., Pant H.R., Shrestha B.K., Kim H.J., Park C.H., Kim C. S., In situ generation of cellulose nanocrystals in polycaprolactone nanofibers, effects on crystallinity, mechanical strength, biocompatibility, and biomimetic mineralization, ACS Appl. Mater. Interf., 2015, 7, 19672-83.

[56] Kamal H., Abd-Elrahim F., Lotfy S., Characterization and some properties of cellulose acetate-co-polyethylene oxide blends prepared by the use of gamma irradiation, J. Radiat. Res. Appl. Sci., 2014, 7, 146-53.

[57] Atila D., Keskin D., Tezcaner A., Cellulose acetate based 3dimensional electrospun scaffolds for skin tissue engineering applications, Carbohyd. Polym., 2015,133, 251-61.

[58] Kendouli S., Sobti N., Bensouissi A., Avci A., Eskizeybek V., Achour S., Modification of cellulose acetate nanofibers with PVP/Ag addition, Mater. Sci. Semicond. Proc., 2014, 28, 13-9.

[59] Deng L., Young R.J., Kinloch I.A., Zhu Y., Eichhorn S.J., Carbon nanofibres produced from electrospun cellulose nanofibres, Carbon, 2013, 58, 66-75.

[60] Rodríguez K., Renneckar S., Gatenholm P., Biomimetic calcium phosphate crystal mineralization on electrospun cellulose-based scaffolds, ACS Appl. Mater. Interf., 2011, 3, 681-9.

[61] Lu P., Hsieh Y.L., Multiwalled carbon nanotube (MWCNT) reinforced cellulose fibers by electrospinning, ACS Appl. Mater. Interf., 2010, 2, 2413-2420.

[62] Kuzmenko V., Naboka O., Gatenholm P., Enoksson P., Ammonium chloride promoted synthesis of carbon nanofibers from electrospun cellulose acetate, Carbon, 2014, 67, 694-703.

[63] Luo Y., Wang S., Shen M., Qi R., Fang Y., Guo R., Cai H., Cao X., Tomás H., Zhu M., Shi X., Carbon nanotube-incorporated multilayered cellulose acetate nanofibers for tissue engineering applications, Carbohyd. Polym, 2013, 91, 419-427.

[64] Demirci S., Celebioglu A., Uyar T., Surface modification of electrospun cellulose acetate nanofibers via RAFT polymerization for DNA adsorption, Carbohyd. Polym, 2014, 113, 200-207.

[65] Liakos I.L., Holban A.M., Carzino R., Lauciello S., Grumezescu A.M., Electrospun fiber pads of cellulose acetate and essential oils with antimicrobial activity, Nanomater., 2017, 7, 84.

[66] Chakraborty P.K., Adhikari J., Saha P., Facile fabrication of electrospun regenerated cellulose nanofiber scaffold for potential bone-tissue engineering application, Int. J. Biol. Macromol., 2019, 122, 644-652.

[67] Lu L., Rininsland F.H., Wittenburg S.K., Achyuthan K.E., McBranch D.W., Whitten D.G., Biocidal activity of a light-absorbing fluorescent conjugated polyelectrolyte, Langmuir, 2005, 21, 10154-9.

[68] Vigo T.L., 11 Antimicrobial Polymers and Fibers, Retrospective and Prospective, ACS Symposium Series, Washington, DC, ACS, 2001, 175-200.

[69] Aggarwal M., Ahammed Z., Alakhverdyants A., Alekseev l., Alford J., Anderson B., Arkhipkin D., Averichev G. S., Balewski J., Barnby L. S., Baumgart S., Higher moments of net proton multiplicity distributions at RHIC, Phys. Rev. Lett., 2010, 105, 022302.

[70] Du J., Tan E., Kim H.J., Zhang A., Bhattacharya R., Yarema K.J., Comparative evaluation of chitosan, cellulose acetate, and polyethersulfone nanofiber scaffolds for neural differentiation, Carbohyd. Polym., 2014, 99, 483-90.

[71] Shi Q., Li Y., Sun J., Zhang H., Chen L., Chen B., Yang H., Wang Z.. The osteogenesis of bacterial cellulose scaffold loaded with bone morphogenetic protein-2, Biomater., 2012, 33, 6644-9.

[72] Xing Q., Zhao F., Chen S., McNamara J., DeCoster M.A., Lvov Y.M., Porous biocompatible three-dimensional scaffolds of cellulose microfiber/gelatin composites for cell culture, Acta Biomaterialia, 2010, 6, 2132-9.

[73] Zaborowska M., Bodin A., Bäckdahl H., Popp J., Goldstein A., Gatenholm P., Microporous bacterial cellulose as a potential scaffold for bone regeneration, Acta Biomaterialia, 2010, 6, 25407.

[74] Zhou C., Shi Q., Guo W., Terrell L., Qureshi A.T., Hayes D.J., Wu Q., Electrospun bio-nanocomposite scaffolds for bone tissue engineering by cellulose nanocrystals reinforcing maleic anhydride grafted PLA, ACS Appl. Mater. Interf., 2013, 5, 3847-54. 
[75] Buschle-Diller G., Cooper J., Xie Z., Wu Y., Waldrup J., Ren X., Release of antibiotics from electrospun bicomponent fibers, Cellulose, 2007, 14, 553-62.

[76] Kim K., Luu Y.K., Chang C., Fang D., Hsiao B.S., Chu B., Hadjiargyrou $M$, Incorporation and controlled release of a hydrophilic antibiotic using poly (lactide-co-glycolide)-based electrospun nanofibrous scaffolds, J. Control. Rel., 2004, 98, 47-56.

[77] da Silva Dannenberg G., Funck G.D., dos Santos Cruxen C.E., de Lima Marques J., da Silva W.P., Fiorentini Â.M., Essential oil from pink pepper as an antimicrobial component in cellulose acetate film, Potential for application as active packaging for sliced cheese, LWT-Food Sci. Technol., 2017, 81, 314-8.

[78] Gouvêa D.M., Mendonça R.C.S., Soto M.L., Cruz R.S, Acetate cellulose film with bacteriophages for potential antimicrobial use in food packaging,LWT-Food Sci. Technol., 2015, 63, 85-91.

[79] Ferfera-Harrar H., Dairi N., Elaboration of cellulose acetate nanobiocomposites using acidified gelatin-montmorillonite as nanofiller, Morphology, properties, and biodegradation studies, Polym. Comp., 2013, 34, 1515-24.

[80] Ferfera-Harrar H, Dairi N. Green nanocomposite films based on cellulose acetate and biopolymer-modified nanoclays, studies on morphology and properties, Iran. Polym. J., 2014, 23, 917-31.

[81] Rodríguez F.J., Galotto M.J., Guarda A., Bruna J.E., Modification of cellulose acetate films using nanofillers based on organoclays, J. Food Eng., 2012, 110, 262-8.

[82] Rodríguez F.J., Coloma A., Galotto M.J., Guarda A., Bruna J.E., Effect of organoclay content and molecular weight on cellulose acetate nanocomposites properties, Polym. Degradat. Stab., 2012, 97, 1996-2001.

[83] de Lima JA., Augusto Pinotti C., Felisberti M.I., do Carmo Gonçalves M., Morphology and mechanical properties of nanocomposites of cellulose acetate and organic montmorillonite prepared with different plasticizers, J. Appl. Polym. Sci., 2012, 124, 4628-35.

[84] Romero R.B., Ferrarezi M.M.F., Leite C.A.P., Alves R.M.V., do Carmo Gonçalves $M$, Influence of the layered silicate type on the structure, morphology and properties of cellulose acetate nanocomposites, Cellulose, 2013, 20, 675-86.

[85] Han D., Gouma P.I., Electrospun bioscaffolds that mimic the topology of extracellular matrix, Nanomed. Nanotechnol. Biol. Med., 2006, 2, 37-41.

[86] Son W.K., Youk J.H., Park W.H., Antimicrobial cellulose acetate nanofibers containing silver nanoparticles, Carbohyd. Polym., 2006, 65, 430-4.

[87] Barua S., Konwarh R., Mandal M., Gopalakrishnan R., Kumar D., Karak N., Biomimetically prepared antibacterial, free radical scavenging poly (ethylene glycol) supported silver nanoparticles as Aedes albopictus larvicide. Adv. Sci., Eng. Med., 2013, 5, 291 8.

[88] Konwarh R., Gogoi B., Philip R., Laskar M., Karak N., Biomimetic preparation of polymer-supported free radical scavenging, cytocompatible and antimicrobial "green" silver nanoparticles using aqueous extract of Citrus sinensis peel, Biointerf., 2011, 84, 33845.

[89] Ali M., Hashim U., Mustafa S., Man Y., Islam K.N., Gold nanoparticle sensor for the visual detection of pork adulteration in meatball formulation, J. Nanomater., 2012, 2012, 1.

[90] Flint D.J., Plumb J.A., Graham D., and Wheate N.J., Brown S.D., Nativo P., Smith J.A., Stirling D., Edwards P.R., Venugopal B., Flint D.J., Plumb J.A., Graham D., Wheate N.J., Gold nanoparticles for the improved anticancer drug delivery of the active component of oxaliplatin, JACS, 2010, 132, 4678-84.

[91] Chen P.C., Li Y.C., Ma J.Y., Huang J.Y., Chen C.F., Chang H.T., Sizetunable copper nanocluster aggregates and their application in hydrogen sulfide sensing on paper-based devices, Scient. Rep., 2016, 6, 24882.

[92] Cheng L., Zhang K., Zhou C.C., Weir M.D., Zhou X.D., Xu H.H., Oneyear water-ageing of calcium phosphate composite containing nano-silver and quaternary ammonium to inhibit biofilms, Int. J. Oral Sci., 2016, 8, 172.

[93] Koo O.M., Rubinstein I., Onyuksel H., Role of nanotechnology in targeted drug delivery and imaging, a concise review, Nanomed. Nanotechnol. Bio. Med., 2005, 1, 193-212.

[94] Li B., Logan B.E., Bacterial adhesion to glass and metal-oxide surfaces, Biointerf., 2004, 36, 81-90.

[95] Perrault S.D., Chan W.C., In vivo assembly of nanoparticle components to improve targeted cancer imaging, Proceed. NAC, 2010, 107, 11194-11199.

[96] Ahamed M., AlSalhi M.S., Siddiqui M, Silver nanoparticle applications and human health, Clinica Chimica Acta, 2010, 411, 1841-1848.

[97] Daniel M.C., Astruc D., Gold nanoparticles, assembly, supramolecular chemistry, quantum-size-related properties, and applications toward biology, catalysis, and nanotechnology, Chemic. Rev., 2004, 104, 293-346.

[98] Lee Y., Choi J.r., Lee K.J., Stott N.E., Kim D., Large-scale synthesis of copper nanoparticles by chemically controlled reduction for applications of inkjet-printed electronics, Nanotechnol., 2008, $19,415604$.

[99] Zhou Y., Kong Y., Kundu S., Cirillo J.D., Liang H., Antibacterial activities of gold and silver nanoparticles against Escherichia coli and bacillus Calmette-Guérin, J. Nanobiotechnol., 2012, 10, 19.

[100] Holt K.B., Bard A.J., Interaction of silver (I) ions with the respiratory chain of Escherichia coli, an electrochemical and scanning electrochemical microscopy study of the antimicrobial mechanism of micromolar $\mathrm{Ag}^{+}$, Biochem, 2005, 44, 13214-23.

[101] Burdușel A.C., Gherasim O., Grumezescu A., Mogoantă L., Ficai A., Andronescu E, Biomedical applications of silver nanoparticles, An up-to-date overview, Nanomat., 2018, 8, 681.

[102] Yan J., Abdelgawad A.M., El-Naggar M.E., Rojas O.J., Antibacterial activity of silver nanoparticles synthesized In-situ by solution spraying onto cellulose, Carbohyd. Polym., 2016, 147, 500-8.

[103] Kittler S., Greulich C., Diendorf J., Koller M., Epple M., Toxicity of silver nanoparticles increases during storage because of slow dissolution under release of silver ions, Chem. Mater., 2010, 22, 4548-54.

[104] Marambio-Jones C., Hoek E.M., A review of the antibacterial effects of silver nanomaterials and potential implications for human health and the environment, J. Nanopart. Res., 2010, 12, 1531-51.

[105] Wang R., Yao Y., Shen M., Wang X., Green synthesis of Au@ Ag nanostructures through a seed-mediated method and their application in SERS, Physicochem. Eng. Asp., 2016, 492, 263-72.

[106] Zhang G., Zheng H., Shen M., Wang L., Wang X., Green synthesis and characterization of Au@ Pt core-shell bimetallic nanoparticles using gallic acid, J. Phys. Chem. Solid., 2015, 81, 79-87.

[107] D’Agostino A., Taglietti A., Grisoli P., Dacarro G., Cucca L., Patrini M., Pallavicini P., Seed mediated growth of silver nanoplates on glass, exploiting the bimodal antibacterial effect by near IR 
photo-thermal action and $\mathrm{Ag}^{+}$release, RSC Adv., 2016, 6, 7041423.

[108] Guan G., Cai Y., Liu S., Yu H., Bai S., Cheng Y., Tang T., Bharathi M. S., Zhang Y. W., Han M. Y., High-Level Incorporation of Silver in Gold Nanoclusters, Fluorescence Redshift upon Interaction with Hydrogen Peroxide and Fluorescence Enhancement with Herbicide, Eur. J., 2016, 22, 1675-81.

[109] Hassan S.S., Carlson K., Mohanty S.K., Canlier A., Ultra-rapid catalytic degradation of 4-nitrophenol with ionic liquid recoverable and reusable ibuprofen derived silver nanoparticles, Environment. Pollut., 2018, 237, 731-9.

[110] Zheng K., Setyawati M.I., Lim T.P., Leong D.T., Xie J., Antimicrobial cluster bombs, silver nanoclusters packed with daptomycin, ACS Nano., 2016, 10, 7934-42.

[111] Slenters T.V., Hauser-Gerspach I., Daniels A.U., Fromm K.M., Silver coordination compounds as light-stable, nano-structured and anti-bacterial coatings for dental implant and restorative materials, J. Mater. Chem., 2008, 18, 5359-62.

[112] Wu C.N, Fuh S. C., Lin S. P., Lin Y. Y., Chen H. Y., Liu J.M., Cheng K. C., TEMPO-oxidized bacterial cellulose pellicle with silver nanoparticles for wound dressing, Biomacromol., 2018, 19, 54454.

[113] Wu M., Ma B., Pan T., Chen S., Sun J., Silver-nanoparticle-colored cotton fabrics with tunable colors and durable antibacterial and self-healing superhydrophobic properties, Adv. Funct. Mater., 2016, 26, 569-76.

[114] Rai M., Yadav A., Gade A., Silver nanoparticles as a new generation of antimicrobials, Biotechnol. Adv., 2009, 27, 76-83.

[115] Tsai T.T., Huang T.H., Chang C.J., Ho N.Y.J., Tseng Y.T., Chen C.F., Antibacterial cellulose paper made with silver-coated gold nanoparticles, Sci. Rep., 2017, 7, 3155.
[116] Nanda A., Saravanan M., Biosynthesis of silver nanoparticles from Staphylococcus aureus and its antimicrobial activity against MRSA and MRSE, Nanomed., Nanotechnol., Biol. Med., 2009, 5, 452-6.

[117] Zhang Y., Peng H., Huang W., Zhou Y., Yan D., Facile preparation and characterization of highly antimicrobial colloid $\mathrm{Ag}$ or $\mathrm{Au}$ nanoparticles, J. Colloid Interf. Sci., 2008, 325, 371-6.

[118] Morones J.R., Elechiguerra J.L., Camacho A., Holt K., Kouri J.B., Ramírez J.T., Yacaman M. J., The bactericidal effect of silver nanoparticles, Nanotechnol., 2005,16, 2346.

[119] Agnihotri S., Mukherji S., Mukherji S., Size-controlled silver nanoparticles synthesized over the range 5-100 nm using the same protocol and their antibacterial efficacy, RSC Adv., 2014, 4, 3974-83.

[120] Sadeghi B., Garmaroudi F.S., Hashemi M., Nezhad H., Nasrollahi A., Ardalan S., Ardalan S., Comparison of the anti-bacterial activity on the nanosilver shapes, nanoparticles, nanorods and nanoplates, Adv. Powde. Technol., 2012, 23, 22-6.

[121] Pal S., Tak Y.K., Song J.M., Does the antibacterial activity of silver nanoparticles depend on the shape of the nanoparticle? A study of the gram-negative bacterium Escherichia coli, Appl. Environment. Microbiol., 2007, 73, 1712-20.

[122] Stohs S., Bagghi D., Oxidative Mechanisms in the Toxicity of Metal lons, Free Radical Biol. Med., 2005, 39, 1267-8.

[123] Lok C.N., Ho C.M., Chen R., He Q.Y., Yu W.Y., Sun H., Tam P. K. H., Chiu J. F., Che C. M., Silver nanoparticles, partial oxidation and antibacterial activities, JBIC J. Biologic. Inorg. Chem., 2007, 12, 527-34. 